Neurosurg Focus 9 (3):E 3, 2000

\title{
Sagittal synostosis
}

\author{
John A. Jane, JR., M.D., Kant Y. Lin, M.D., and John A. Jane, SR., M.D., Ph.D., F.R.C.S.(C) \\ Department of Neurosurgery, University of Virginia Health Sciences Center, Charlottesville, Virginia
}

\begin{abstract}
Sagittal synostosis causes predictable malformations depending on the specific suture location that fuses. Anterior fusion causes frontal bossing, whereas posterior fusion causes an occipital knob. Complete sagittal synostosis results in deformity both anteriorly and posteriorly. Variants of each type exist and therefore surgical correction must be tailored to the individual patient. Examples of the different forms of sagittal synotsosis are discussed, and the various surgical techniques available are detailed.
\end{abstract}

KeY WORDS • craniosynostosis • sagittal synostosis

The first reported surgical procedure for correction of craniosynostosis was performed in 1890 by Lannelongue ${ }^{8}$ who advocated releasing, but not resecting, the fused suture (see also Cohen $\left.{ }^{1}\right)$. Two years later, Lane ${ }^{7}$ described the first strip craniectomy with extraction of the fused suture. The child in this case died postoperatively, and there followed a period during which surgical correction fell out of favor, until Mehner ${ }^{9}$ in 1921 described the first successful use of strip craniectomy to remove a fused suture. Concurrently, and in contrast, Faber and Towne ${ }^{3}$ expounded a more radical craniectomy. However, these early procedures were performed not for cosmesis but to improve or salvage intellectual function. It was not until the work of Tessier ${ }^{13,14}$ and Rougerie, et al., ${ }^{11}$ in the late 1960s and early 1970s that cosmetic objectives began to be receive primary emphasis.

Over the past 30 years, various techniques for craniosynostosis have been refined considerably. Although a number of principles are universally accepted, techniques are not standardized. The individual surgeon's preferences, born of training, experience, and collegial interaction, continue to typify the surgical correction of synostoses. The methods and preferences described in this article are a distillation of experience most notably that of Milton Edgerton, John Persing, Kant Lin, and John Jane, Sr. gained over the last three decades at a single institution, the University of Virginia, .

\section{Compensatory Changes Associated With Single-Suture Fusion}

Sommerring ${ }^{12}$ in 1800 described the anatomy of the suture and postulated not only its role in normal skull growth but also the effects of early closure. In the early- to mid-19th century Otto,${ }^{10}$ and later, Virchow ${ }^{15}$ asserted that premature closure of sutures prevented growth perpendicular to the suture and was accompanied by compensatory growth at others.

However, this compensatory growth is not ameliorat- ing; the compensations cause skull deformities whose morphology structures adhere to certain rules. ${ }^{2}$ First, compensatory growth is greatest at adjacent sutures. Second, if the adjacent suture is more or less parallel to the fused suture, the compensatory growth will be symmetrical. For example, when the metopic suture is fused, the growth occurs symmetrically on both sides of the sagittal suture (Fig. 1 left). The third rule states that if the adjacent suture is more or less perpendicular to the fused suture, the majority of the compensatory growth occurs from the bone distal to the fused suture. Again using the example of metopic synostosis, the majority of the compensatory growth at the coronal suture occurs in the parietal, not the frontal bone.

The primary lesson derived from these rules is that the malformation results from more than simple inhibition of

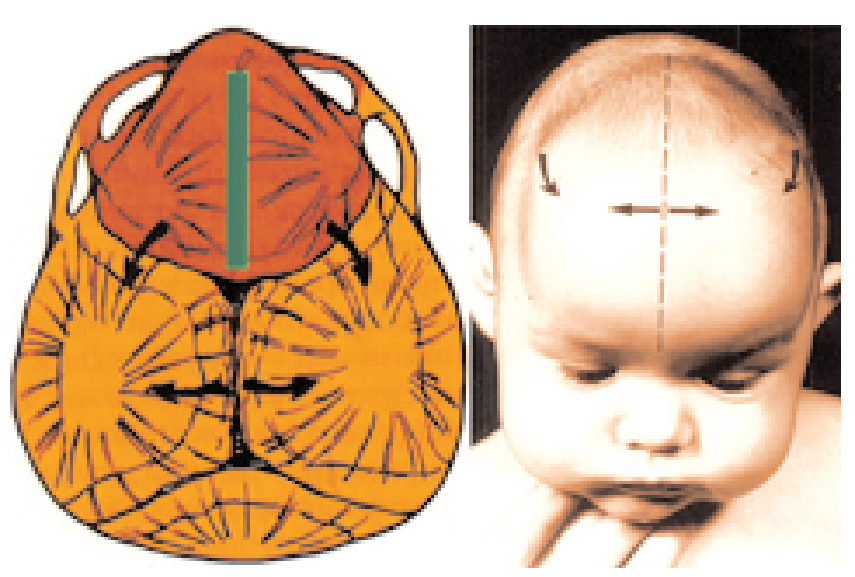

Fig. 1. Left: Artist's illustration of metopic synostosis. Green line denotes area of premature closure. Arrows indicate areas of compensatory growth. Right: Photograph of infant with anterior sagittal synostosis, showing characteristic frontal bossing. Arrows indicate areas of compensatory growth. 
J. A. Jane, Jr., K. Y. Lin, and J. A. Jane, Sr.

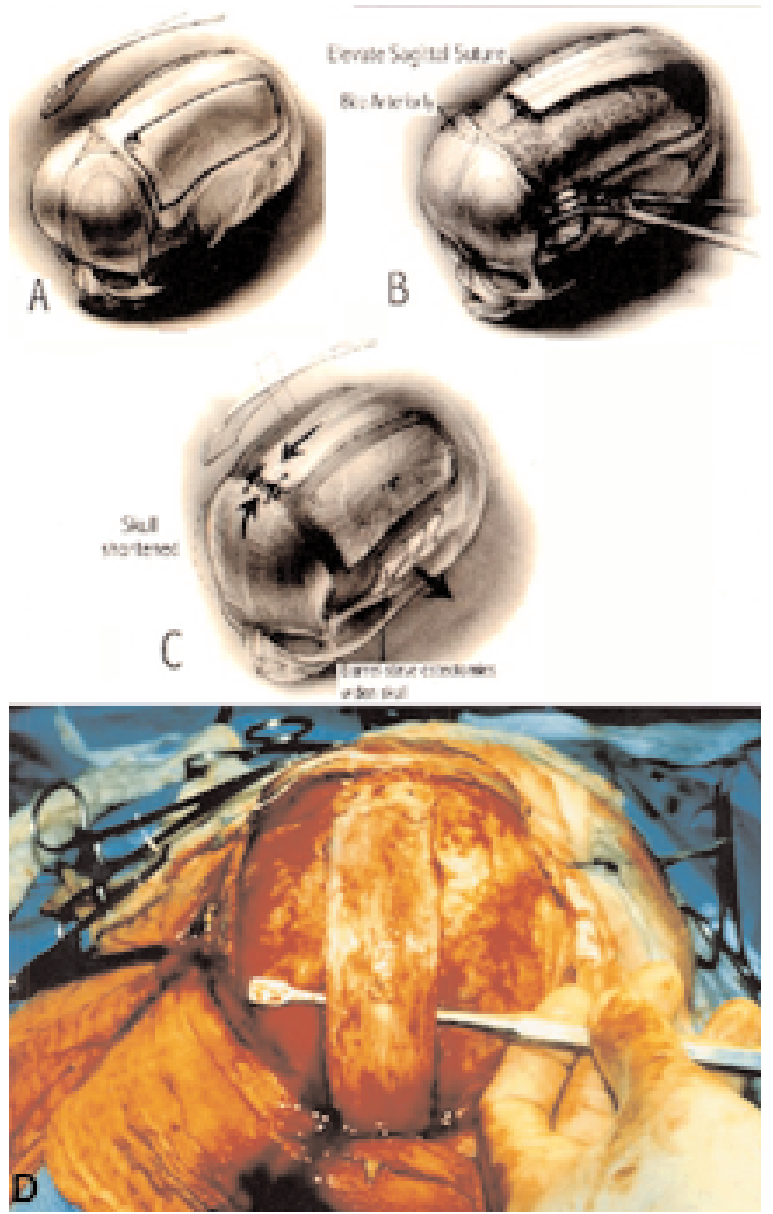

Fig. 2. Artist's illustrations depicting stages in the anterior $\pi$ procedure for surgical correction of anterior sagittal synostosis in an infant. A: Biparietal craniotomy is performed. B: Craniotomy is extended across the coronal suture, and the bone along the sagittal suture is elevated from the sagittal sinus. C: The remaining bone is reapproximated, the biparietal flaps are refashioned, and barrel-stave osteotomies are performed to widen the skull. D: Photograph obtained during anterior $\pi$ procedure for correction of anterior sagittal synostosis in an infant. The sagittal suture is shown being elevated from the underlying dura and sinus.

growth perpendicular to the fused suture. Surgery, then, must correct not only the fused suture, but also the compensatory changes. Ideally, surgery should be performed prior to fusion of the nonpathological sutures. Early repair benefits from the pliability of infant skull, which diminishes significantly near the end of the 1st year. Some consideration is given to the infant's size, and generally surgery is delayed until the child is 6 months of age.

\section{Sagittal Synostosis}

Sagittal synostosis, the most common form of craniosynostosis, is characterized by several frequently recurring types of presentation; each requires a surgical procedure tailored to the individual case. ${ }^{4-6}$ Premature closure of the sagittal suture results in a long head, termed dolichocephaly or scaphocephaly. Sagittal synostosis has many different forms. The nature of the compensatory

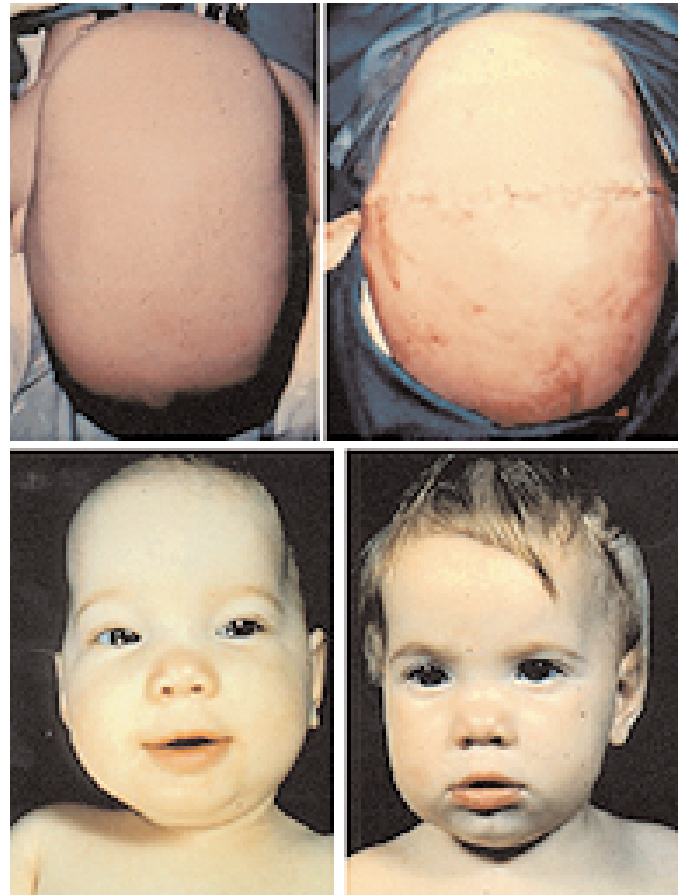

Fig. 3. Upper: Photographs obtained in an infant before (left) and after (right) anterior $\pi$ procedure for correction of anterior sagittal synostosis. Postoperative photographs demonstrates shortening and widening of the skull. Lower: Photographs obtained in an infant before (left) and after (right) anterior $\pi$ procedure. Note reduction of frontal bossing in postoperative photograph.

growth, and thus the resulting deformity, depends on the location along the sagittal suture at which fusion prematurely takes place; this location may be anterior, posterior, or both anterior and posterior (that is, complete).

Anterior Sagittal Suture Closure and Frontal Bossing. When the anterior portion of the sagittal suture closes prematurely, the resulting compensatory growth causes frontal bossing (Fig. 1 right). An extensive craniotomy is required to correct this overgrowth of the frontal bone. The craniotomy must achieve expansion of the narrowed skull, shortening of the protracted anteroposterior distance, and reduction or elimination of the bossing. To accomplish these goals, the so-called anterior $\pi$ procedure is performed (Fig. 2).

Biparietal flaps are fashioned, the anterior and posterior limits of which are the coronal and lambdoid sutures. The coronal suture is rongeured, leaving a craniotomy in the shape of a $\pi$ (Fig. 2B). Note that the pathological sagittal suture is not excised; the operation focuses on the areas of compensatory growth rather than the fused suture. The remaining elements are united slanting the frontal bone posteriorly, thus correcting the skull length and the frontal bossing. Barrel-stave osteotomies are fashioned in the temporal bone so that when the remaining bone elements are brought together, the width of the skull can expand.

Of key importance is that the sagittal sinus must be separated from the overlying bone before bringing the bone together (Fig. 2D). The dura underlying the frontal bone is also elevated. This decreases the risk of morbidity by eliminating possible kinking of the sagittal sinus. The pro- 

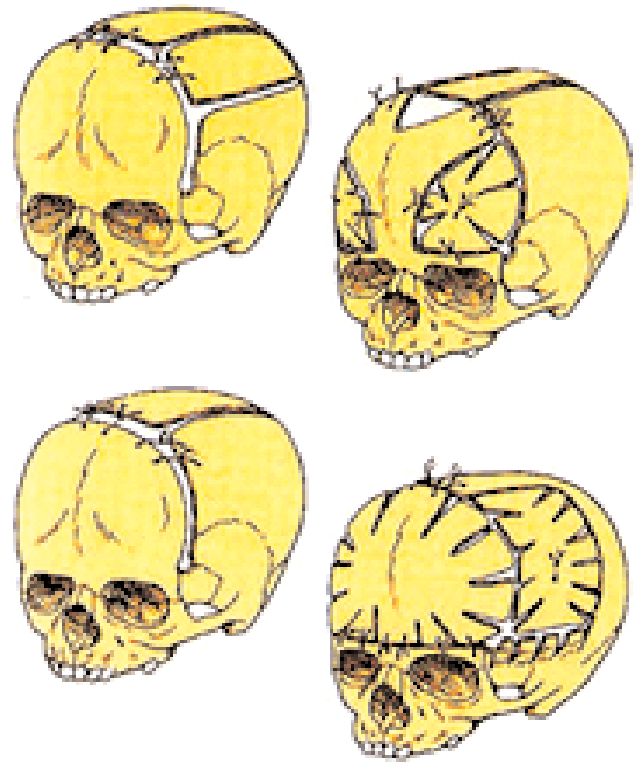

Fig. 4. Artist's illustration showing variants on the anterior $\pi$

cedure also changes the relationship of the pathological dura to the overlying skull and may interrupt the signals that would otherwise cause restenosis. The end result is a more pleasing round head (Fig. 3).

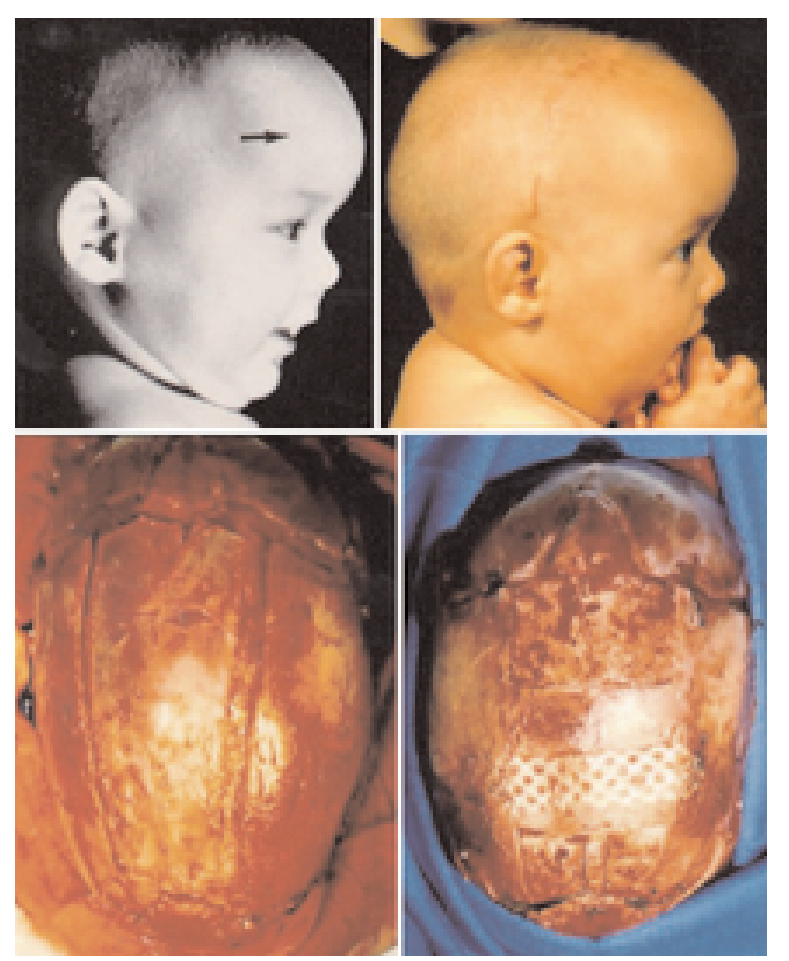

Fig. 5. Upper: Photographs obtained in an infant before (left) and after (right) anterior $\pi$ procedure to correct pronounced frontal bossing. Approximation of normal skull contour has been achieved postoperatively. Lower: Pre- (left) and postoperative (right) photographs demonstrating alternative techniques to anterior $\pi$ procedure for treatment of anterior sagittal synostosis.

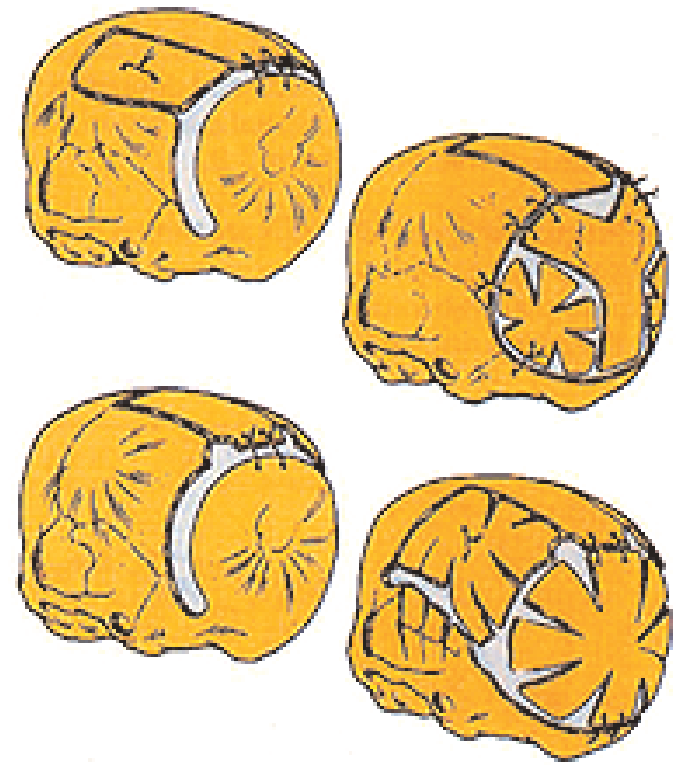

Fig. 6. Artist's illustration depicting different surgical procedures for correction of premature posterior sagittal suture closure in an infant.

There are a number of variations on this procedure depending on the specific compensatory changes in skull shape that have occurred (Fig. 4). When frontal bossing is pronounced, the frontal bone must be removed and reshaped using radial osteotomies and careful fracturing of the frontal bone. The goal is a normal skull contour (Fig.

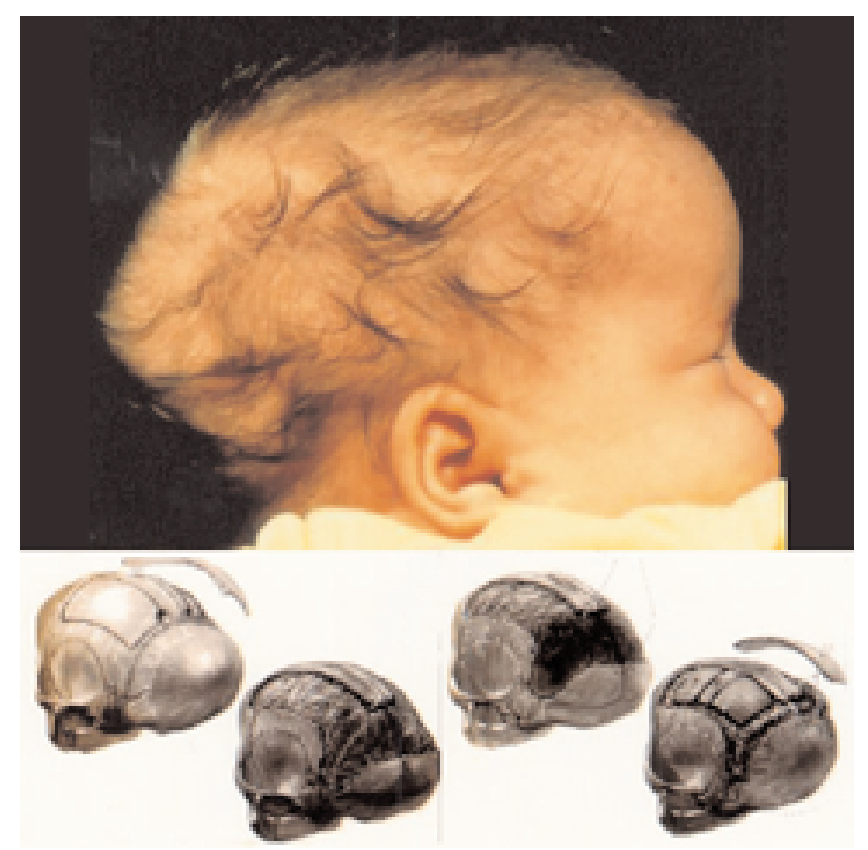

Fig. 7. Upper: Photograph of infant with posterior sagittal synostosis (lateral view) demonstrating occipital knob. Lower: Artist's illustration depicting stages in the reverse $\pi$ procedure for correction of posterior sagittal synostosis. 

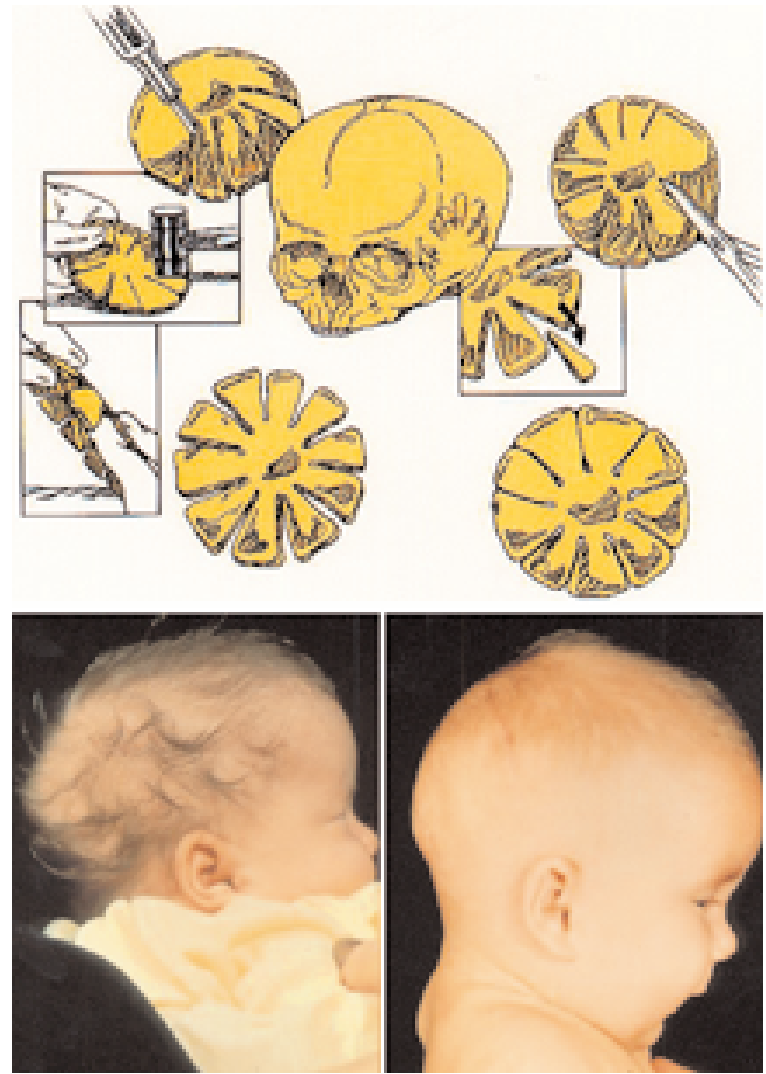

Fig. 8. Upper: Artist's illustration depicting stages in radial osteotomy procedure for correction of occipital knob. Lower: Photographs obtained in an infant before (left) and after (right) surgical removal of the occipital knob, a variety of posterior sagittal synostosis. Note approximation of normal contour in postoperative photograph.
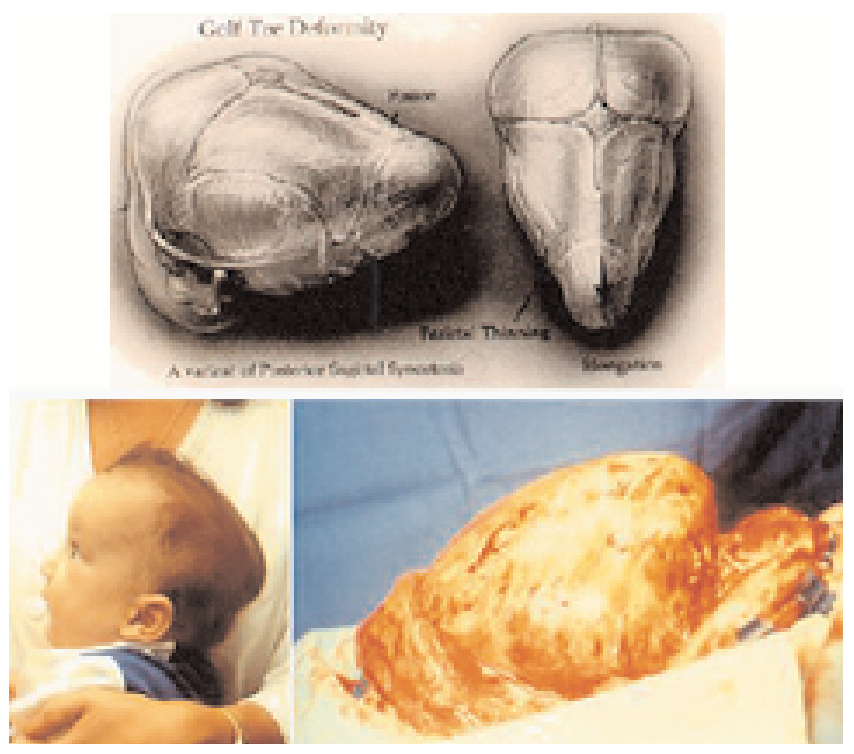

Fig. 9. Artist's illustration (upper left and right) depicting golf tee deformity, an exaggerated form of the occipital knob, and pre(lower left) and intraoperative (lower right) photographs obtained in an infant with this deformity.

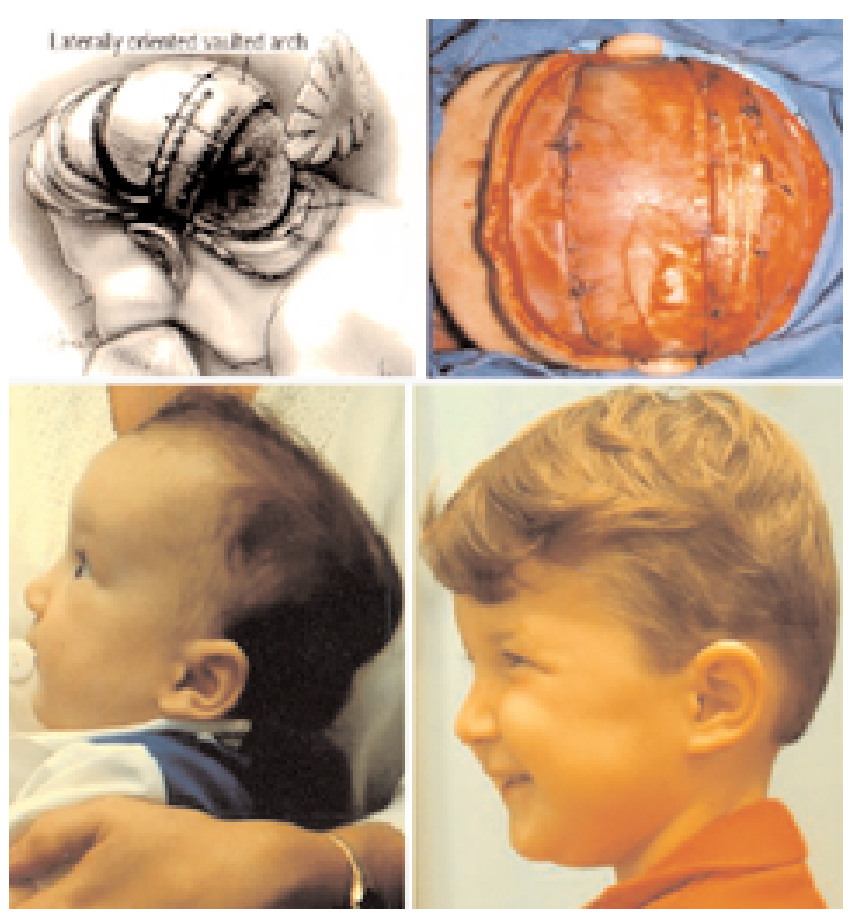

Fig. 10. Artist's illustration (upper left) and intraoperative photograph (upper right) depicting stages in surgical procedure for correction of golf tee deformity, a variantof posterior sagittal synostosis. Lower: Photographs obtained in an infant with golf tee deformity (posterior sagittal synostosis) before (left) and after (right) surgical correction.

5 upper). To that end, strict adherence to rehearsed techniques should be prohibited. At times, other techniques must be used instead of the anterior $\pi$ procedure (Fig. 5 lower). The skull may be foreshortened by removing a biparietal flap that contains the sagittal suture. This flap is then shortened and rotated $90^{\circ}$ to increase the width of the skull. The skull on either side of the coronal and lambdoid sutures is rongeured; after the remaining bone edges are united, the skull is rendered shorter and rounder.

Posterior Sagittal Suture Closure: Occipital Knob, Golf Tee, and Bathrocephalic Deformities. Closure of the posterior portion of the sagittal suture occurs less commonly than anterior closure and requires different surgical approaches (Fig. 6). There are several variants on the basic disorder, each demanding individual consideration. The most basic deformity is the so-called occipital knob (Fig. 7 upper). In such a circumstance, the occipital bone becomes the site of compensatory overgrowth because it is located distal and perpendicular to the fused suture. To correct the deformity, a reverse $\pi$ procedure may be used (Fig. 7 lower). After the biparietal flaps are removed, the bone is rongeured across the posterior portion of the sagittal suture and across the lamboids, similar to the anterior $\pi$ approach. The resultant craniotomy appears as a reversed $\pi$. Again, care must be taken to release the dura along the sagittal suture. Radial osteotomies with removal of triangular wedges from the occipital bone may be required to correct the knob (Fig. 8 upper). The results can be quite good, and the normal contour can be reestablished (Fig. 8 lower). 

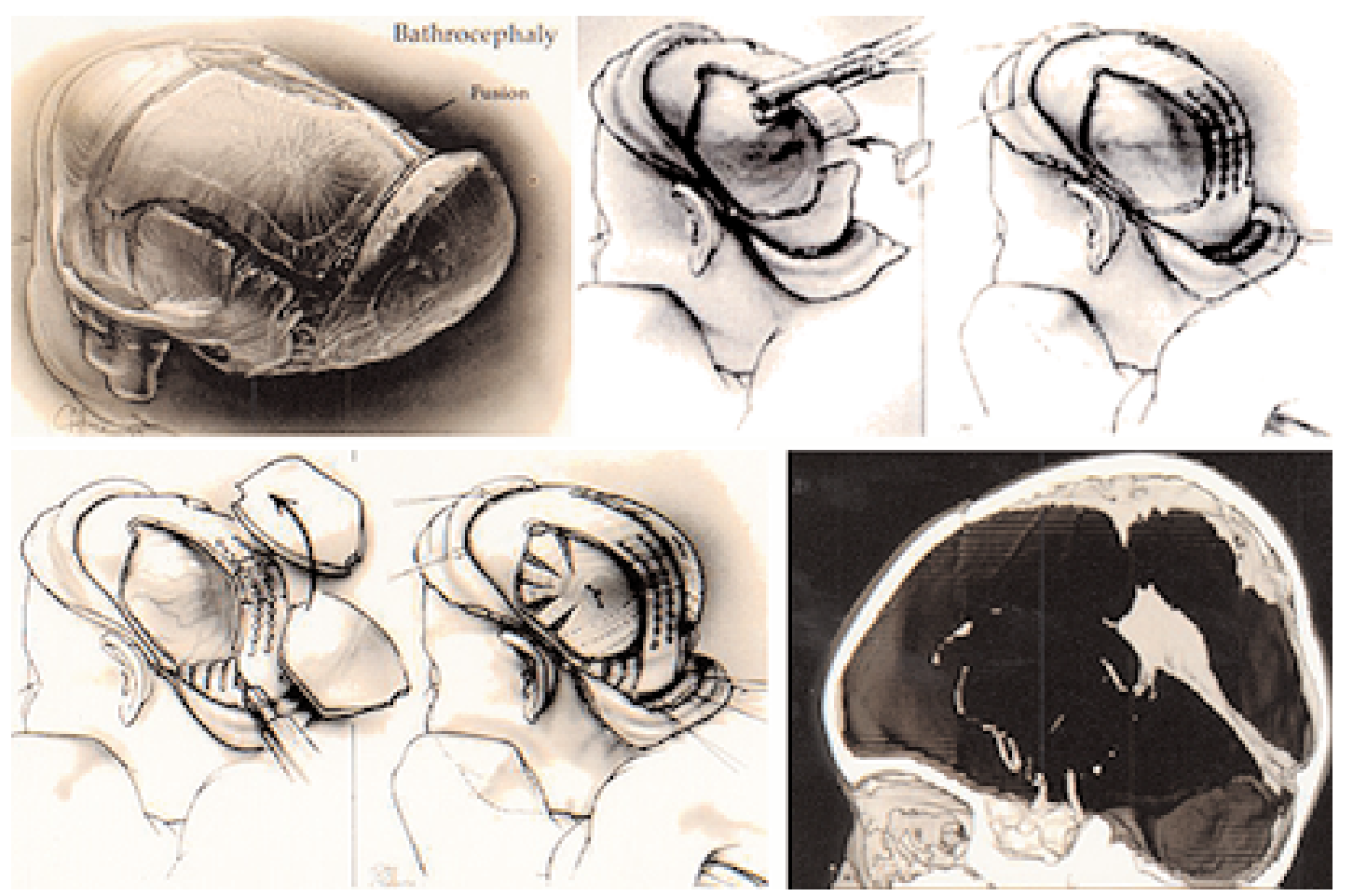

Fig. 11. Upper Left: Artist's illustration of an infant with bathrocephaly, an extreme consequence of premature posterior closure of the sagittal suture. Upper Center and Right: Artist's illustrations depicting stages in the surgical procedure for correction of bathrocephaly in an infant. After biparietal flaps are created, the sagittal suture is separated from underlying dura and lengthened by insertion of a bone graft (upper center). The lengthened medial bone strip, or paramedian vault, is secured with absorbable plate and screws (upper right). Lower Left and Center: Artist's illustrations depicting final remodeling required for surgical correction of bathrocephaly. Lower Right: Computerized tomography venogram obtained preoperatively in an infant, demonstrating location of the torcular herophili.

The "golf tee" deformity is more than simply an exaggerated form of the occipital knob (Fig. 9). The skull is narrower posteriorly and protrudes more prominently. In addition, the unfused anterior portion of the sagittal suture may widen the parietal bone anteriorly accentuating the occipital narrowing. To correct this more dramatic deformity, not only must the skull must be shortened; the occipital region must be widened as well. An occipital craniotomy is performed and a paramedian biparietal flap containing the sagittal suture is fashioned. Creation of a laterally oriented vaulted arch accomplishes the widening of the region, and radial osteotomies allow the occipital bone to be refashioned (Fig. 10).

Bathrocephaly, another variant of posterior sagittal synostosis, is characterized by the appearance of a podium in the occipital region (Fig. 11 upper right). The posterior portion of the parietal bone slants inferiorly while the occipital bone juts superiorly. The aim of surgical correction is to achieve not only a shorter skull, but also one that has a normal contour. After biparietal flaps are established, the sagittal suture is separated from the underlying dura (Fig. 11 upper center and right). A paramedian vault is created that normalizes the relationship between the posterior parietal and occipital bones (Fig. 11 lower left and center). Radial cuts across the lambdoid sutures allow the occipital bone to be fractured outward, resulting in a wider occipital region. Particular care must be taken when working around the transverse sinus and torcular herophili. Com-

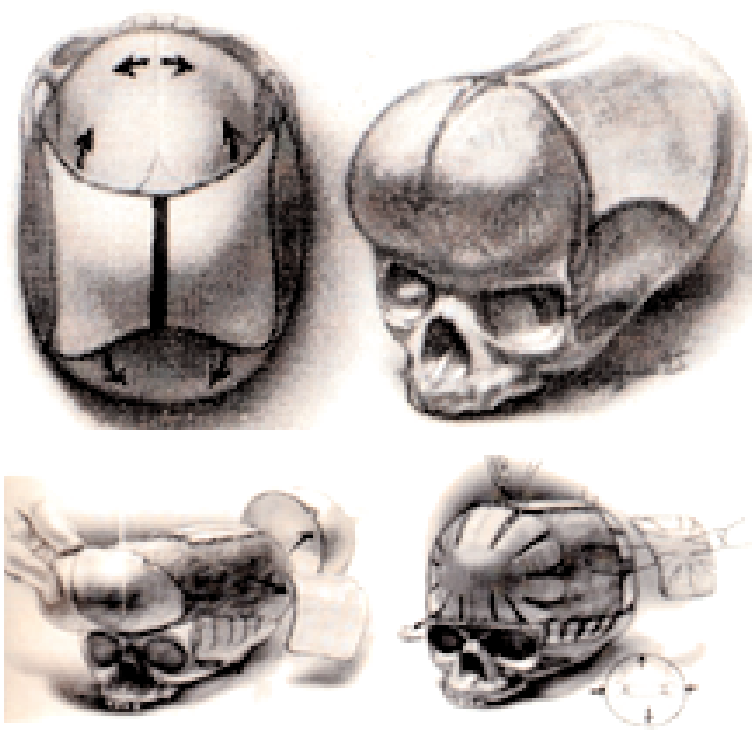

Fig. 12. Upper: Artist's illustration depicting combined (anterior and posterior) sagittal suture deformity. Arrows indicate areas of compensatory growth. Lower: Artist's illustration depicting stages in the extensive craniotomy procedure required to correct frontal bossing and occipital knob associated with complete (anterior and posterior) sagittal suture deformity. 
puterized tomography venography can be particularly useful in establishing preoperatively the location of these important venous structures (Fig. 11 lower right).

Complete Sagittal Synostosis. In its most extreme form, complete closure of the sagittal suture causes both anterior and posterior deformity (Fig. 12 upper). Surgical correction must involve the entire skull, correcting the scaphocephaly, frontal bossing, and occipital knob (Fig. 12 lower). A near-calveriectomy must be fashioned, removing bifrontal, bioccipital, and two parietal flaps. The flaps are remodeled using radial osteotomies and replaced to create a shorter and rounder skull. Barrel-stave osteotomies in the parietotemporal region can also increase skull width.

\section{CONCLUSIONS}

Certain clinical rules predict the specific manifestations of sagittal synostosis. Because the manifestations are varied, surgical correction must focus, not on the fused suture itself, but on the specific compensatory changes that accompany it. The techniques discussed herein are offered not as absolutes, but as alternatives. Just as the entity of sagittal synostosis is protean, so must the treatments be. The goal, in the end, is a normal skull contour.

\section{References}

1. Cohen MM Jr: History, terminology, and classification of craniosynostosis, in Cohen MM Jr, Maclean RE (eds): Craniosynostosis: Diagnosis, Evaluation, and Management, ed 2. New York: Oxford University Press, 2000, pp 103-111

2. Delashaw JB, Persing JA, Broaddus WC, et al: Cranial vault growth in craniosynostosis. J Neurosurg 70:159-165, 1989

3. Faber HK, Towne EB: Early craniectomy as a preventive measure in oxycephaly and allied conditions. With special reference to the prevention of blindness. Am J Med Sci 173:701-711, 1927
J. A. Jane, Jr., K. Y. Lin, and J. A. Jane, Sr.

4. Francel PC, Jane JA: Image reconstruction and craniofacial repair, in Salman M (ed): Current Techniques in Neurosurgery, ed 2. Philadelphia: Current Medicine, 1996, pp 30-51

5. Jane JA, Persing JA: Neurosurgical treatment of craniosynostosis, in Cohen MM Jr, Maclean RE (eds): Craniosynostosis: Diagnosis, Evaluation, and Management, ed 2 New York: Oxford University Press, 2000, pp 209-227

6. Jane JA Sr, Jane JA Jr: Treatment of craniosynostosis. Clin Neurosurg 43:139-162, 1996

7. Lane LC: Pioneer craniectomy for relief of mental imbecility due to premature sutural closure and microcephalus. JAMA 18:49-50, 1892

8. Lannelongue M: De la craniectomie dans la microcephalie. CR Acad Sci 110:1382-1385, 1890

9. Mehner A: Beiträge zu den Augenveränderungen bei der Schädeldeformität des sog. Turmschädels mit besonderer Berücksichtigung des Röntgenbildes. Klinische Monatsbl Augenheilk 61:204, 1921

10. Otto AW: Lehrbuch der pathologischen Anatomie des Menschen und der Thiere. Berlin: Rücker, 1830

11. Rougerie J, Derome P, Anquez L: [Craniostenosis and craniofacial dysmorphism. Principles of a new method of treatment and its results]. Neurochirurgie 18:429-440, 1972 (Fr)

12. Sommerring ST: Vom Baue des menschlichen Körpers. Leipzig: Voss, 1800

13. Tessier P: The definitive plastic surgical treatment of the severe facial deformities of craniofacial dysostosis. Crouzon's and Apert's diseases. Plast Reconstr Surg 48:419-442, 1971

14. Tessier P: [Total facial osteotomy. Crouzon's syndrome, Apert's syndrome: oxycephaly, scaphocephaly, turricephaly]. Ann Chir Plast 12:273-286, 1967 (Fr)

15. Virchow R: Ueber den Cretinismus, namentlich in Franken. Und ueber pathologische Schädelformen. Verh Phys Med Gesamte Wurzburg 2:230-270, 1851

Manuscript received August 8, 2000.

Accepted in final form August 16, 2000.

Address reprint requests to: John A. Jane, Jr., M.D., Department of Neurological Surgery, Box 212, University of Virginia Health Sciences Center, Charlottesville, Virginia 22908. email: jaj2k@virginia.edu. 